\title{
Produção de biomassa da gramínea vetiver (Chrysopogon zizanioides (L.) Roberty) em diferentes espaçamentos após 420 dias do plantio
}

Damiany dos Santos Manoel ${ }^{1}$

Lilian Vilela Andrade Pinto ${ }^{2}$

Rafael Xavier de Souza ${ }^{3}$

Odilon França de Oliveira Neto 4

Michender Werison Motta Pereira 5

\section{1 | Introdução}

A produção da gramínea vetiver, reclassificada como Chrysopogon Zizanioides (L.) Roberty, se sobressai em relação a outras gramíneas como brachiaria e capim gordura devido a não necessidade de acompanhamento da espécie e a grande resistência dela à alterações ambientais, como clima, tipo de solo, etc. (PEREIRA, 2006). A facilidade de plantio e sua característica de ser uma planta não invasora fazem da espécie uma gramínea ideal e versátil para ser utilizada na proteção de encostas contra erosão (PEREIRA, 2006), extração de óleos essenciais (CASTRO; RAMOS, 2002) e também para alimentação animal, pois possui um elevado valor proteico (TRUONG et al., 2008).

A matéria seca (MS) é a fração sólida que pode ser convertida em nutrientes. Quando a água da amostra de uma forragem é removida através de secagem, obtendo a matéria seca, pode-se realizar comparações de produção entre plantas forrageiras.

Segundo McKenzie et al. (2002), citado por Pereira (2006), solo e clima têm grande influência sobre o crescimento, o desenvolvimento e a produção de plantas forrageiras. Pereira et al. (2006) ressaltam que técnicas de manejo ajudam a garantir a produtividade das pastagens. Dentre as ações de manejo que interferem na produtividade, destaca-se o espaçamento de plantio, variável que foi avaliada neste estudo.

Em regiões com clima tropical, o vetiver cresce ligeiramente e produz um valor de biomassa maior que 100 toneladas de matéria seca ha/ano (DANH et al., 2009, citado por ALMEIDA, 2011). Essa matéria seca pode ser utilizada na fabricação de esteiras, divisórias, como cobertura de construções rurais rústicas e para a cobertura do solo, como palhada (CASTRO; RAMOS, 2002), além de fornecer matéria prima à confecção de artesanatos, uma das principais atividades geradoras de trabalho e renda de diversas comunidades que vivem dessa cultura.

Neste sentido, o objetivo do presente trabaIho é avaliar a produção de biomassa do capim vetiver (Vetiveria zizanioides) em diferentes espaçamentos após 420 dias do plantio.

\footnotetext{
IFSULDEMINAS, campus Inconfidentes/MG, e-mail: damiany.ifsuldeminas@hotmail.com IFSULDEMINAS, campus Inconfidentes/MG, e-mail: lilianvap@gmail.com UNICAMP, Campinas/SP, e-mail: rafael.ifsm@gmail.com IFSULDEMINAS, campus Inconfidentes/MG, e-mail: odiloneto@hotmail.com UNICAMP, Campinas/SP, e-mail: michender.ambiental@gmail.com
} 


\section{2 | Materiais e métodos}

Oexperimento foidesenvolvido no município de Inconfidentes/MG, na Fazenda-Escola do Instituto Federal de Educação, Ciência e Tecnologia do Sul de Minas Gerais, campus Inconfidentes.

O município de Inconfidentes apresenta altitude média de $855 \mathrm{~m}$ e posição geográfica de $22^{\circ} 19^{\prime \prime} 00^{\prime}$ de latitude S e $46^{\circ} 19^{\prime \prime} 40^{\prime}$ longitude W. Segundo a classificação de Koëppem, o clima da região é do tipo tropical úmido com duas estações bem definidas: chuvosa (outubro a março) e seca (abril a setembro), com médias anuais de $1.800 \mathrm{~mm}$ de precipitação e $19^{\circ} \mathrm{C}$ de temperatura.

A área em que foi realizado o experimento, localiza-se em uma encosta experimental com declividade média de $30^{\circ}$ e rampa de $6 \mathrm{~m}$. As parcelas foram instaladas com a dimensão de $6 \mathrm{~m}$ de comprimento e $2,5 \mathrm{~m}$ de largura, com bordaduras de $0,5 \mathrm{~m}$ de cada lado da parcela para controlar o efeito dos diferentes tratamentos, totalizando uma área útil de $9 \mathrm{~m}^{2}$

Para avaliar o efeito do espaçamento de plantio da gramínea vetiver na produção de matéria seca da gramínea, foi utilizado o delineamento estatístico em blocos casualizados, com 9 tratamentos (espaçamentos de plantio) e 3 blocos/repetições.

As mudas foram produzidas em saquinhos de polietileno de $5,5 \times 19 \mathrm{~cm}$, empregando-se substrato feito de esterco bovino previamente curtido e terra de subsolo peneirada, na proporção de $1 / 3$ de esterco e 2/3 de terra. As covas para o plantio tiveram diâmetro de 0,15 m por $0,10 \mathrm{~m}$ de profundidade e foram feitas com cavadeira.

Para a determinação da produção total de matéria seca (MS), foram realizados cortes rente ao solo aos 420 dias do plantio.

A produção de MS foi determinada mediante corte e pesagem das plantas presentes na área útil das parcelas de cada espaçamento. Foram recolhidas aleatoriamente 10 amostras da parte vegetativa por parcela, que tiveram peso médio de 200 a 300g. Em seguida, essas amostras foram colocadas em sacos de papel, identificadas e encaminhadas ao laboratório de bromatologia do IFSULDEMINAS, campus Inconfidentes, onde foram pesadas (matéria úmida). A análise foi realizada seguindo o método de secagem convencional. Esse método utiliza estufa com circulação de ar forçada a $65^{\circ} \mathrm{C}$, o material permaneceu nesse local durante 8 horas. Após esse período, a amostra foi encaminhada novamente à balança para pesagem do peso seco (massa de matéria seca).

Os dados obtidos foram processados e submetidos à análise de variância (ANAVA) seguindo o delineamento em blocos ao acaso e as médias comparadas pelo teste Scott-knott a $5 \%$ de probabilidade usando o programa Sisvar (FERREIRA, 2008).

\section{3 | Resultados e discussão}

Em acordo com os dados obtidos, nota-se que não houve diferença estatística na produtividade de matéria seca do capim vetiver para nenhum dos espaçamentos testados (Figura 1). Entretanto, o espaçamento $1,0 \mathrm{~m} \times 0,30 \mathrm{~m}$ apresentou maior quantidade de biomassa seca, 52,70 ton.ha ${ }^{-1}$.

Ressalta-se que a gramínea vetiver apresenta alta produtividade de matéria seca, acima de 20 ton.ha-1 ${ }^{-1}$ com exceção no tratamento que utilizou o maior espaçamento, 2,om x 0,45m $(8,92$ ton.ha-1). Casale (2013) e Zanine et al. (2009) observaram valores de matéria seca de 20 ton.ha ${ }^{-1}$ e de 22,10 ton.ha ${ }^{-1}$ para as espécies Brachiaria ruzienzis e Brachiaria brizantha, respectivamente, valores de produtividade considerados altos pelos autores para serem utilizados nas entrelinhas do plantio de café como opção de manejo (CASALE, 2013) e na consorciação com a cultura do milho, resultando em menor compactação do solo (FREITAS et al., 2005, citado por SILVA; FERRARI, 2012).

No que tange à estabilização e proteção de encosta/talude, o melhor espaçamento é o $1,5 \mathrm{~m} \times 0,15 \mathrm{~m}$ por ter apresentado menor perda de solo (SOUZA et al., 2012). Neste espaçamento a produção de matéria seca de vetiver foi de 21,38 t.ha $^{-1}$, valor de biomassa seca considerada alta por Casale (2013) e Zanine et al. (2009), não diferente estatisticamente dos valores de matéria seca encontrada nos outros espaçamentos avaliados. Assim, recomendase o espaçamento de plantio de $1,5 \mathrm{~m} \times 0,15 \mathrm{~m}$ para o cultivo do vetiver. 


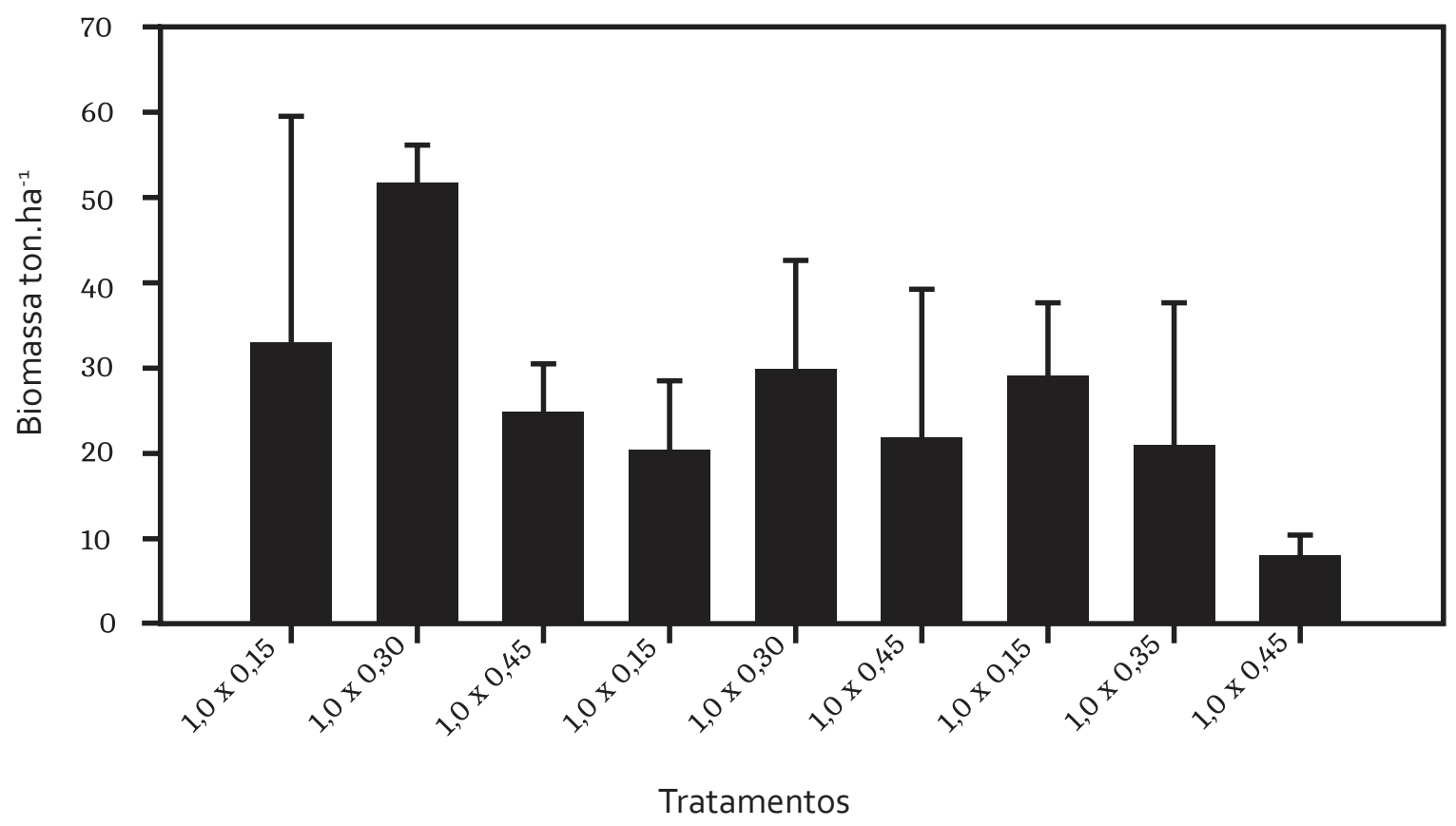

Figura 1: Produtividade de matéria seca da gramínea vetiver com 420 dias de desenvolvimento da parte vegetativa plantadas em diferentes espaçamentos, Inconfidentes/MG.

Fonte: Elaboração própria.

\section{4 | Conclusão}

A produção de biomassa das plantas de capim vetiver não foi influenciada pelos espaçamentos de plantio avaliados.

Recomenda-se o espaçamento de plantio de $1,5 \mathrm{~m} \times 0,15 \mathrm{~m}$ para o cultivo do vetiver por promover valores de matéria seca considerados altos e menor perda de solo, conforme dados observados na literatura.

\section{Agradecimentos}

À Fundação de Amparo à Pesquisa do estado de Minas Gerais (FAPEMIG) pelo apoio financeiro e pela bolsa de iniciação científica.

\section{Referências bibliográficas}

ALMEIDA, E. A. P.. Avaliação do potencial da espécie vetiveria zizanioides na fitorremediação de metais-traço presentes em ambientes aquáticos. 2011. [? p.].

Dissertação (Programa de Pós-graduação em Saneamento, Meio Ambiente e Recursos Hídricos). Universidade Federal de Minas Gerais, Belo Horizonte.
CASTRO, L. O. de ; RAMOS, R. L. D..

Principais gramíneas produtoras de óleos essenciais: Cymbopogon citratus (DC) Stapf., capim-cidró, Cymbopogon martinii (Rox.) J.F. Watson, palma-rosa, Cymbopogon nardus (L.) Rendle, citronela, Elyonurus candidus (Trin.) Hack. , capim-limão, Vetiveria zizanioides (L.) Nash, vetiver. Porto Alegre: FEPAGRO, 2002. 31 p. (Boletim FEPAGRO, 11).

CASALE, H. Cafeicultura com mato no pé: considerações sobre o valor e a importância da matéria orgânica para a saúde do cafeeiro, a qualidade do grão e a produtividade. AGRO DBO, ano 9, n. 42, p.32-35, mar. 2013.

FERREIRA, D. SISVAR: um programa para análises e ensino de estatística. Revista Symposium, Lavras, v. 6, p. 36-41, 2008.

PEREIRA, A. R. O uso do Vetiver na estabilização de taludes e encostas. Boletim Técnico, n. 03. Belo Horizonte, 2006. Disponível em: <www.deflor.com.br/ portugues/pdf/boletim3.pdf>.

Acesso em: 29 fev. 2012. 
PEREIRA, O. G. et al. Conservação de

Forragens como opção para o Manejo de

Pastagens. In: Simpósios da $43^{\text {a }}$ Reunião Anual

da SBZ. Anais... João Pessoa: [s.n.], 2006.

SILVA, S. F.; FERRARI, J. L. Descrição botânica, distribuição geográfica e potencialidades de uso da brachiaria brizantha (hochst. ex. a.

rich) stapf. In: Enciclopédia Biosfera, Centro

Científico Conhecer - Goiânia, v.8, N.14i p.

2012 314. Disponível em <www.conhecer.org.

br/enciclop/2012a/agrarias/descricao.pdf>.

Acessado em 14/03/13.

SOUZA, R. X. et al. Influência de diferentes classes de precipitação na perda de solo por erosão em encosta coberta com capim vetiver. Resumos expandidos. In: CONGRESSO NACIONAL DE MEIO AMBIENTE DE POÇOS DE CALDAS, $9^{\circ}$, 2012, Poços de Caldas.

TRUONG, P.; VAN, T. V., PINNER, E. Sistema de aplicação vetiver: manual de referência técnica. 2 ed. Vietnam, 2008. 116p.

ZANINE, A. M. et al. Comportamento ingestivo de vacas Girolandas em pastejo de Brachiaria brizantha e Coast-cross. Revista Brasileira de Saúde em Produção Animal, v.10, n.1, p.85-95, 2009. 